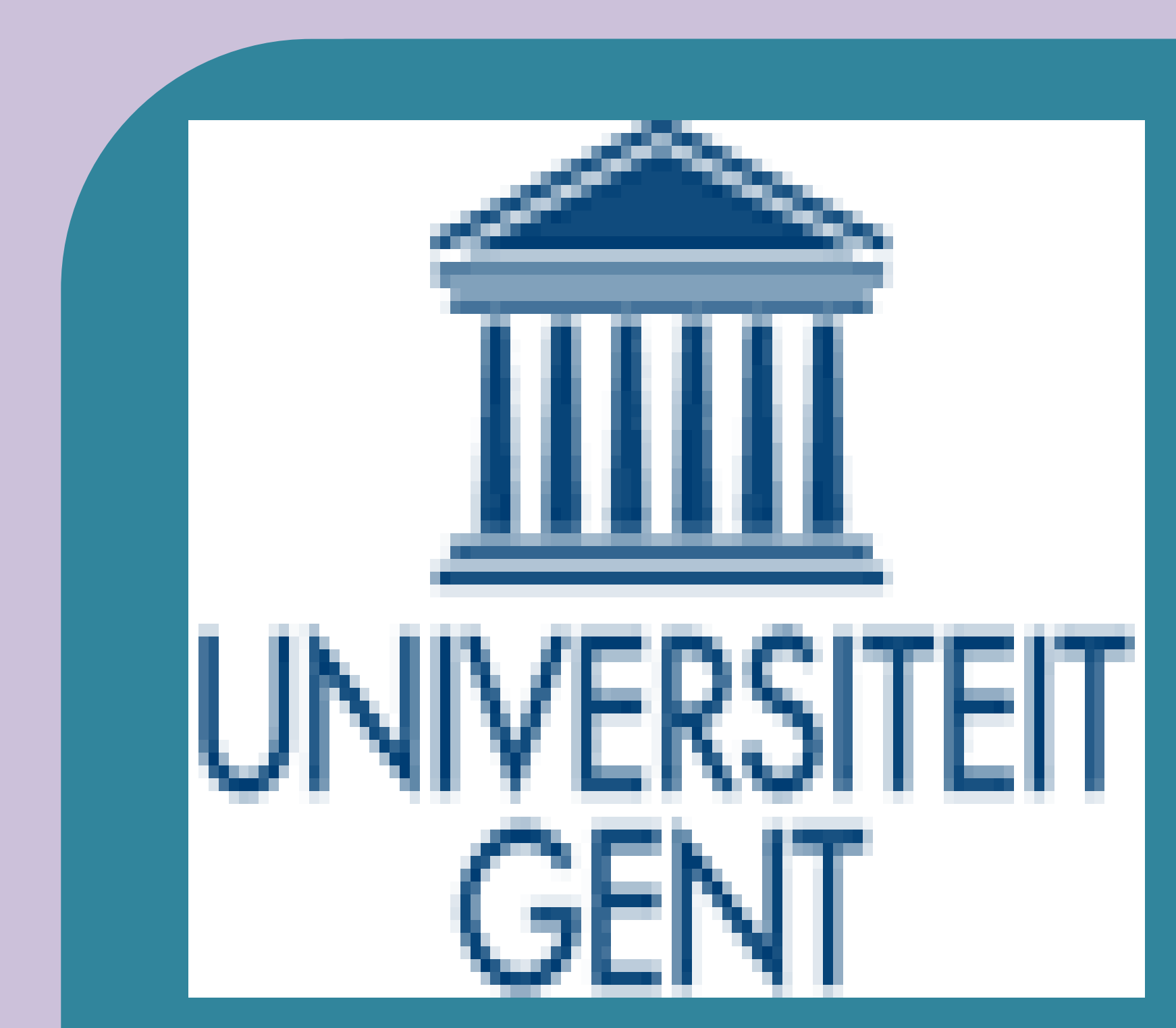

\title{
When mother and daughter become father and son.
}

Tatjana Sajevets ${ }^{1}$, Charlotte Verroken ${ }^{1}$, Gunter Heylens² ${ }^{2}$ Elfride De Baere ${ }^{3}$, Guy T'Sjoen ${ }^{1,2}$

${ }^{1}$ Department of Endocrinology, ${ }^{2}$ Department of Sexology and Gender Problems, ${ }^{3}$ Centre for
Medical Genetics, Ghent University Hospital, De Pintelaan 185, 9000 Ghent, Belgium.

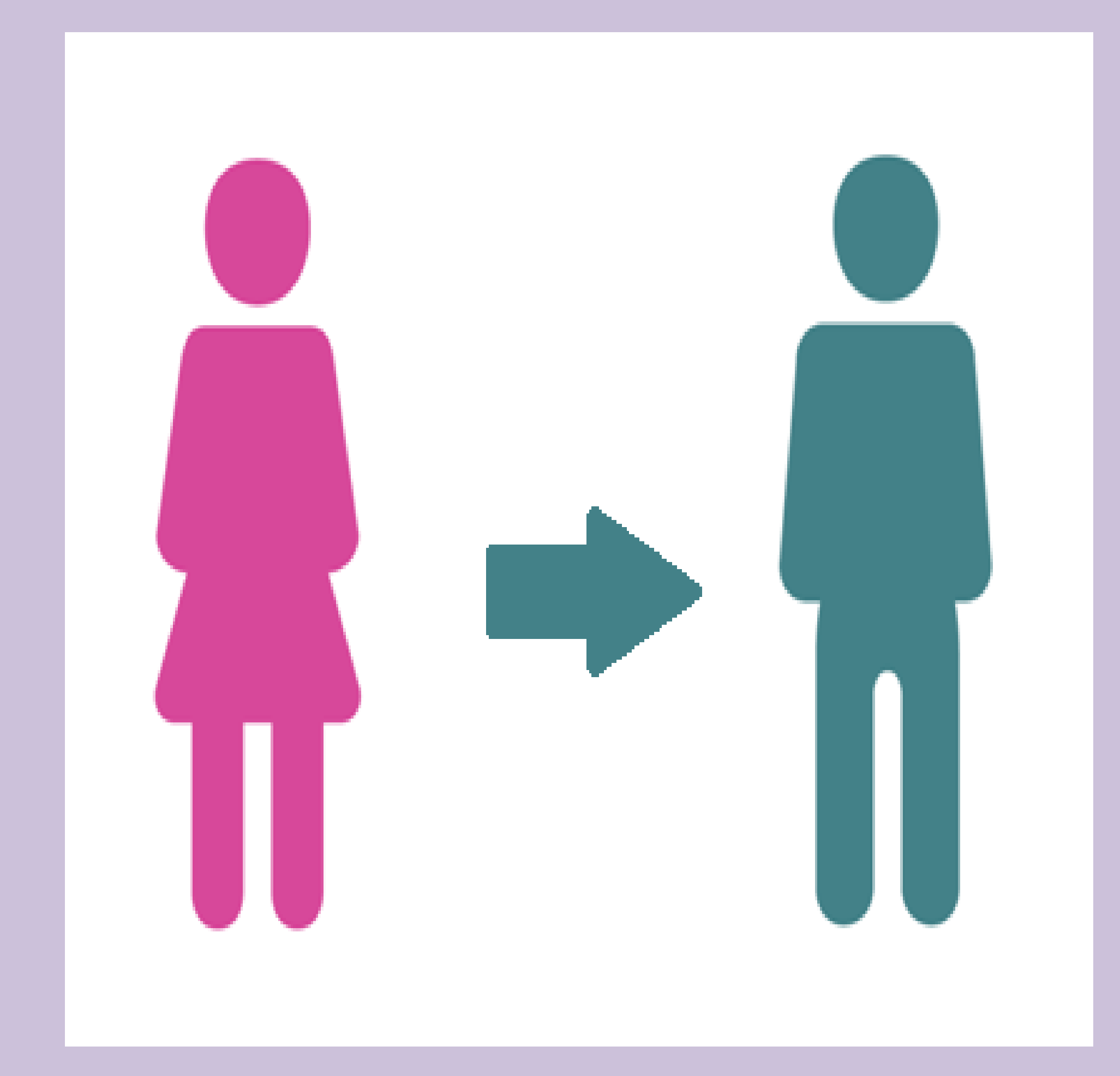

The mother becomes a father:

The mother was diagnosed with gender dysphoria (GD) at the age of 47 .

As an only child she suffered from emotional, physical and sexual abuse by her parents. From the age of 3 , she fantasized being a boy and started behaving like one. During later youth the genderdysphoric feelings were repressed. She married at the age of 18 . One year later she became pregnant, but after giving birth she felt no emotional connection with the baby-girl.

A diagnosis of GD was established in 2004. The client started with cross-sex hormone therapy. In 2006 he underwent bilateral subcutaneous mastectomy and endoscopic hysterectomy/ovariectomy. Metadoioplasty followed by phalloplasty were performed in 2007 and 2009, respectively. In 2012, the sex reassignment surgery was completed with the placement of an erectile device and testicular prostheses.

\section{The daughter becomes a son:}

The daughter was diagnosed with GD at age 31.

She was also an only child. She has no traumatic childhood memories. GD became obvious from the age of 8 , when she started behaving like a boy and sought for male playmates. During later youth she suffered from psychological problems such as panic attacks and social phobia.

A diagnosis of GD was established in 2007. In 2008, cross-sex hormone therapy was started. Bilateral subcutaneous mastectomy and endoscopic

hysterectomy/ovariectomy were performed in 2009. Because of a postoperative

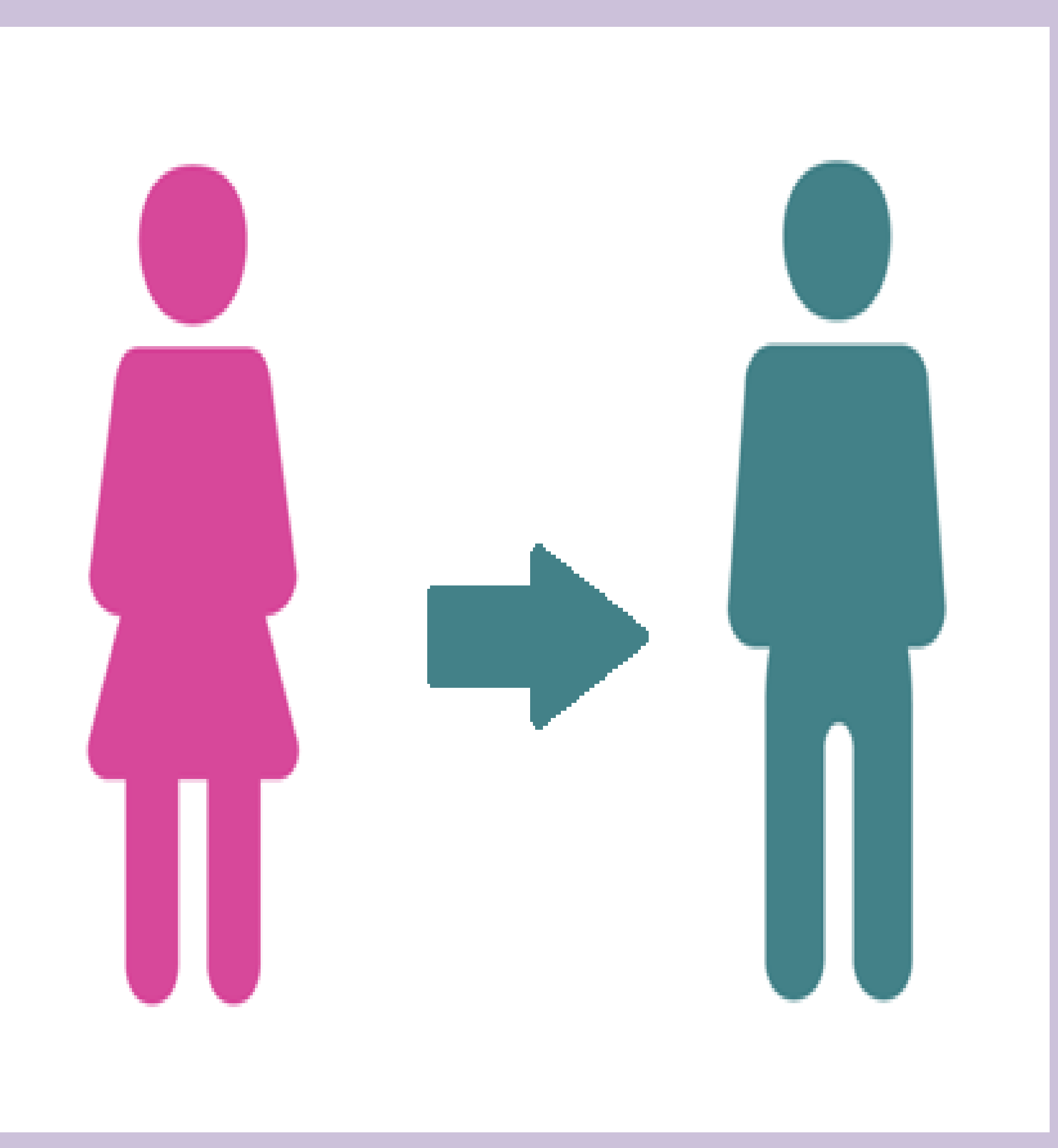
complication after the mastectomy genital surgery is temporarily postponed.

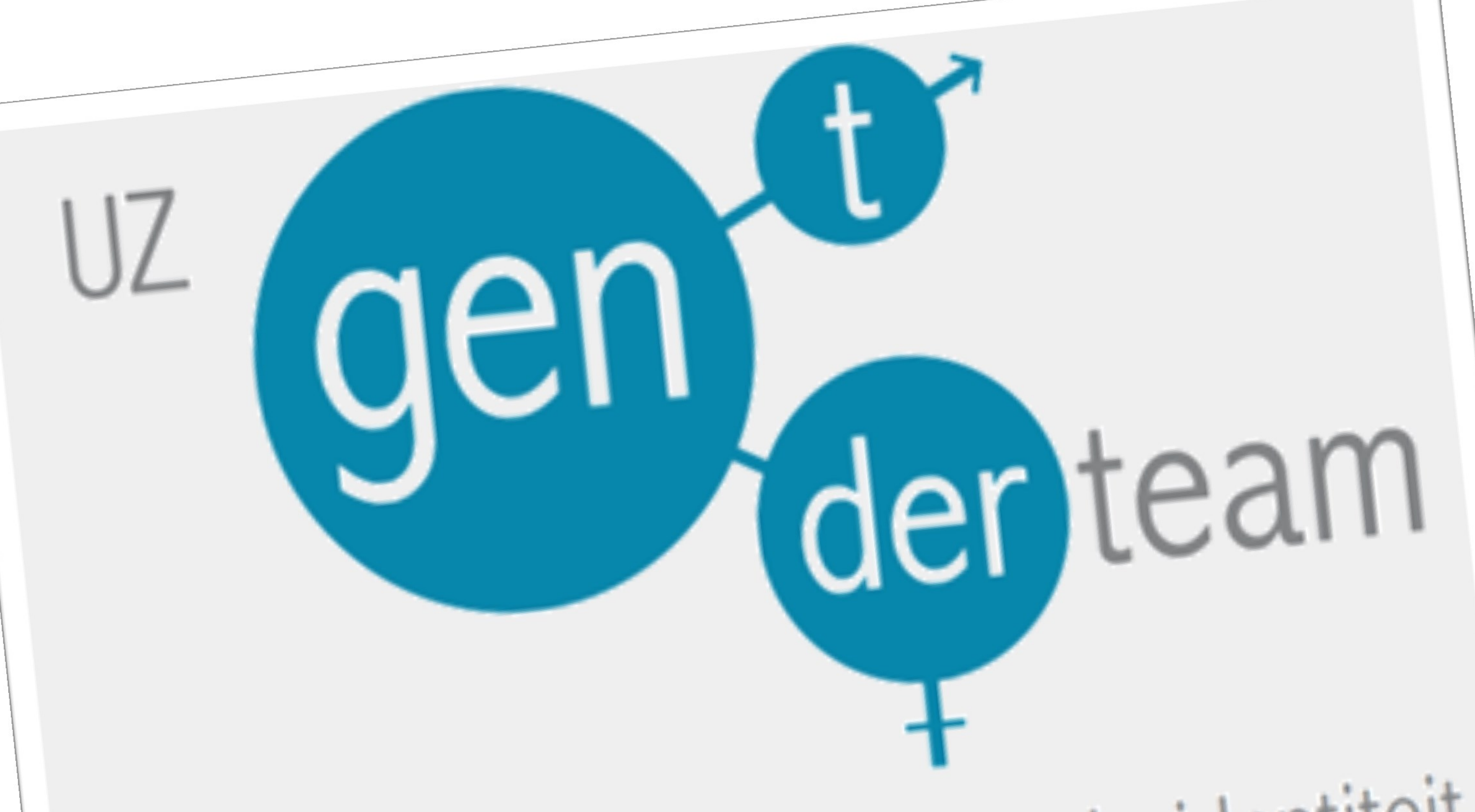

geslachtsontwikkeling - genderidentiteit

\section{Conclusions:}

Both father and son are doing well since their transition. Genetic testing showed an aberrant female array CGH profile with a 650kb duplication in chromosome 15q26.3 both in father and son and a $\sim 100 \mathrm{~kb}$ deletion in $7 p 14.1$ in the GLI3 gene in father. Further research into the clinical relevance of this finding or its connection with GD is currently ongoing. This findings however seems to be of limited relevance. 